\title{
The value of simple tests for peristaltic activity in hiatus hernia
}

\author{
S. J.A. POWIS and J. LEIGH COLLIS
}

Queen Elizabeth Hospital, Birmingham

\begin{abstract}
A study has been made of oesophageal peristaltic activity as viewed at barium swallows, in an effort to see whether this is helpful in assessing the type and degree of oesophageal lesions associated with hiatus hernia. It has not been possible to establish a clinical usefulness from such testing as the frequency with which peristaltic upset occurs is too marginal.
\end{abstract}

Siegel and Hendrix (1963) showed that all patients with heartburn developed symptoms with acid perfusion of the oesophagus. Manometric studies performed during perfusion demonstrated one of the following types of motor abnormality: (1) increased amplitude and duration of peristalsis; (2) spastic non-peristaltic contraction ; and (3) increased tone.

A practical modification of this investigation subsequently reported (Donner, Silbiger, Hookman, and Hendrix, 1966) demonstrated that if barium is acidified ( $p \mathrm{H} \quad 1 \cdot 7)$ cine-radiography showed aperistalsis, non-peristaltic contraction, or delayed emptying in $98.7 \%$ of patients with heartburn. This was proposed as a single test for detection of peptic oesophagitis.

The present survey was undertaken to evaluate further the use of acidified barium in the diagnosis of oesophageal lesions.

\section{METHOD}

The investigation studies a total of 194 patients, the data being adequate in 164 of these, who were divided into four groups:

I Normal controls, who had no clinical or radiological evidence of disease in the oesophagus, stomach or duodenum, but were attending hospital for other reasons (22 patients).

II Pre-operative patients with a radiologically proven hiatus hernia. Of the $\mathbf{4 0}$ patients in this group, 27 had no stricture (a) and 13 had a peptic stricture (b).

III Seventy-six patients subjected to operation for hiatus hernia between one and 13 years previously (mean two years six months).

IV A group of 26 patients with various pathologies affecting the oesophagus (achalasia, carcinoma, etc.).
All patients had barium swallows performed using both normal barium ( $p \mathrm{H} \mathrm{3.85)} \mathrm{(Micropaque)} \mathrm{and} \mathrm{acid}$ barium ( $p H 1 \cdot 3)$; this was specially prepared to have the same consistency by adding $\mathrm{N} / 12 \mathrm{HCl}$ to normal barium solution.

With the patients lying supine, timed measurements were made of the first co-ordinated peristalsis seen after deglutition (first wave) and of oesophageal clearance, declared when no more barium was visible in the oesophagus. If barium remained at one and a half minutes, the result was recorded as 'not clear at 90 sec.'.

The volume of barium swallowed was not measured, but was one normal mouthful. This was cleared with a single swallow.

The barium swallows on all patients in groups II, III, and IV were viewed and evaluated by the senior author (J. L. C.), and all those on patients in group I were performed by the same radiologist (Dr. W. J. Adam).

All patients in group II had oesophagoscopies performed to assess the degree of macroscopic oesophagitis, and 20 of those without a stricture (group IIa) and 11 of those with a stricture (group IIb) had oesophageal biopsies performed to establish the stage of microscopic inflammation. This was in order to demonstrate any difference there may be in the response of the inflamed oesophagus to normal and acid barium.

\section{RESULTS}

FIRST WAVE (Table I). In all groups the range was wide, but the majority had their first wave between 5 and 15 seconds.

In the pre-operative group, the time of the wave bore no relationship to the severity of symptoms or to the macroscopic or microscopic grade of oesophagitis. The presence of a stricture did not necessarily delay the appearance of the first wave. 
T A B L E I

FIRST WAVE TIMES WITH NORMAL BARIUM

\begin{tabular}{c|c|c}
\hline Group & Range (sec.) & $\begin{array}{c}\% \text { Between } \\
5 \text { and 15 sec. }\end{array}$ \\
\hline II & $6-50$ & $86 \cdot 3$ \\
III & $3-20$ & $88 \cdot 0$ \\
III & $5-16$ & $92 \cdot 3$ \\
IV & $5-30$ & $86 \cdot 2$ \\
& $7-30$ & $90 \cdot 4$ \\
\hline
\end{tabular}

Despite a wide range in times of the first wave, the majority of patients in all groups have their first wave between 5 and 15 seconds.

The first wave was delayed in just over half of the individuals in groups I to III by acid barium (Table II), but the delay was small and the range was large.

T A B L E I I

EFFECT OF ACID BARIUM ON FIRST WAVE

\begin{tabular}{|c|c|c|c|c|}
\hline Group & $\%$ Delayed & $\underset{\text { (sec.) }}{\text { Mean Delay }}$ & \multicolumn{2}{|c|}{$\begin{array}{l}\text { Range of Delay } \\
\text { (sec.) }\end{array}$} \\
\hline $\begin{array}{l}\text { I } \\
\text { IIa } \\
\text { IIb } \\
\text { III } \\
\text { IV }\end{array}$ & $\begin{array}{l}54 \cdot 5 \\
56.0 \\
53.8 \\
51 \cdot 7 \\
28.6\end{array}$ & $\begin{array}{l}2 \cdot 6 \\
3 \cdot 3 \\
5 \cdot 5 \\
3 \cdot 6 \\
3 \cdot 8\end{array}$ & $\begin{array}{r}-10 \text { tc } \\
-8 \\
-3 \text { tc } \\
-30 \text { tc } \\
-10 \\
-5 \text { tc }\end{array}$ & $\begin{array}{l}+12 \\
+18 \\
+22 \\
+20 \\
+17\end{array}$ \\
\hline
\end{tabular}

The first wave is delayed in just over half the patients in groups I to III, but the mean delay is small and the range too large to make this of any diagnostic value.

In post-operative patients the primary wave bore no relationship to the clinical results, and in many experiencing dysphagia the primary wave was not delayed.

It seems that the time of the first wave and the delay sometimes caused by acid barium is of no value in assessing the nature of oesophageal disease.

ClEARANCE (Tables III and IV) In normal controls the mean clearance time was similar with normal and acid barium, but with a wide variation, $50 \%$ clearing acid barium more quickly than normal barium. Only $22.7 \%$ had a slower clearance time with acid barium.

\section{T A B L E I I I}

OESOPHAGEAL CLEARANCE WITH NORMAL AND ACID BARIUM

\begin{tabular}{|c|c|c|c|c|}
\hline \multicolumn{3}{|c|}{ Normal } & \multicolumn{2}{|c|}{ Acid } \\
\hline Group & $\begin{array}{l}\% \text { Clear } \\
\text { at } 90 \text { sec. }\end{array}$ & $\begin{array}{l}\text { Mean Times } \\
\text { of Clearance }\end{array}$ & $\begin{array}{l}\% \text { Clear } \\
\text { at } 90 \text { sec. }\end{array}$ & $\begin{array}{l}\text { Mean Times } \\
\text { of Clearance }\end{array}$ \\
\hline $\begin{array}{l}\text { I } \\
\text { II } \\
\text { IIb } \\
\text { III } \\
\text { IV }\end{array}$ & $\begin{array}{r}63.6 \\
93.5 \\
75.0 \\
72.7 \\
100.0\end{array}$ & $\begin{array}{l}36 \cdot 1 \\
24 \cdot 6 \\
44 \cdot 9 \\
36 \cdot 5 \\
38 \cdot 0\end{array}$ & $\begin{array}{r}72 \cdot 7 \\
93 \cdot 2 \\
66 \cdot 3 \\
75 \cdot 9 \\
100 \cdot 0\end{array}$ & $\begin{array}{l}36.0 \\
31.4 \\
49.6 \\
32.5 \\
36.0\end{array}$ \\
\hline
\end{tabular}

There is no significant difference in the number of patients who clear the oesophagus in under 90 seconds with both normal and acid barium, but there is a delay in clearance in group II with acid barium.
T A B L E I V

EFFECT OF ACID BARIUM ON CLEARANCE

\begin{tabular}{|c|c|c|c|}
\hline Group & $\%$ Quicker & $\%$ Slower & $\%$ Same Time \\
\hline $\begin{array}{l}\text { I } \\
\text { IIa } \\
\text { IIb } \\
\text { III } \\
\text { IV }\end{array}$ & $\begin{array}{l}50 \cdot 0 \\
48 \cdot 2 \\
30 \cdot 7 \\
31 \cdot 0 \\
38 \cdot 5\end{array}$ & $\begin{array}{l}22.7 \\
41 \cdot 6 \\
23.0 \\
41 \cdot 0 \\
54 \cdot 8\end{array}$ & $\begin{array}{r}27 \cdot 3 \\
10 \cdot 2 \\
46 \cdot 3 \\
28 \cdot 0 \\
6 \cdot 7\end{array}$ \\
\hline
\end{tabular}

The delay caused by acid barium in group IIa is significant, but asless than half the patients exhibited this delay it is of little clinical $\vec{\omega}$ application.

In the pre-operative patients with a hiatus hernia $\overrightarrow{\vec{x}}$ and stricture, $23 \%$ were delayed by acid barium N (46.3\% cleared acid and normal barium at the $\rightarrow$ same rate), whereas if no stricture was present $c$ cे clearance was delayed in $41.6 \%$. This delay is statistically significant $(P<0 \cdot 05)$, but the delay in $\frac{\text { O }}{2}$ patients with a stricture is not. Not surprisingly, $\vec{c}$ patients in group II, with a stricture, clear more slowly than those without, with both normal and acid barium.

Post-operative patients also cleared acid and. normal barium in similar times, but the time of $\square$ clearance bore no relationship to the clinical results of operation.

Patients with various pathologies likewise cleared normal and acid barium in similar times. $\mathbb{D}$

There was no relationship between symptoms, $\stackrel{\vec{P}}{\vec{F}}$ oesophagoscopy findings and clearance times.

\section{CONCLUSIONS}

The first wave is of no value in assessing the presence of oesophageal lesions, especially hiatus으 hernia, with oesophagitis.

The time of clearance has a wide variation in 0 the normal and diseased oesophagus. The only factor of statistical significance which delays clear- 8 ance of both normal and acid barium is a stricture. In patients without a stricture the delay caused응 by acid barium was also significant, but as only $D$ $41 \cdot 6 \%$ demonstrated such a delay this is of little을. clinical value.

The findings of Donner et al. (1966) have not been supported, and this test, when used in 0 patients with hiatus hernia, cannot be recommended for the diagnosis of oesophageal lesions 0 with or without oesophagitis.

Our thanks are due to Dr. W. J. Adam, of the Warwick Hospital, who kindly collected the control group and carried out their tests.

\section{REFERENCES}

Donner, M. W., Silbiger, M. L., Hookman, P., and Hendrix, T. R. (1966). Acid-barium swallows in the radiographic evaluation of clinical esophagitis. Radiology, 87, 220 .

Siegel, C. I., and Hendrix, T. R. (1963). Esophageal motor abnormalities induced by acid perfusion in patients with heartburn. $J$. clin. Invest., 42, 686 . 